\title{
Hypoxaemia in chronic obstructive pulmonary disease patients during a commercial flight
}

\author{
A. Akerø*, C.C. Christensen*,\#, A. Edvardsen" ${ }^{*}$ and O.H. Skjønsberg*
}

ABSTRACT: The aim of the study was to investigate hypoxaemia in chronic obstructive pulmonary disease patients during a commercial flight.

The effect of a commercial flight, lasting $\mathbf{5} \mathrm{h} \mathbf{4 0} \mathrm{min}$, on arterial blood gas levels and symptoms in 18 chronic obstructive pulmonary disease patients with a pre-flight percutaneous oxygen saturation of $\geqslant 94 \%$ and self-reported ability to walk $50 \mathrm{~m}$ without severe dyspnoea was studied.

The arterial oxygen tension $\left(\mathrm{Pa}, \mathrm{O}_{2}\right)$ decreased from sea level to cruising altitude $(10.3 \pm 1.2$ versus $8.6 \pm 0.8 \mathrm{kPa}$ ), but, thereafter, except for one patient, remained stable throughout the flight. During light exercise, however, there was further desaturation (percutaneous oxygen saturation $90 \pm 4$ versus $87 \pm 4 \%$ ). After $4 \mathrm{~h}$, a decrease in arterial carbon dioxide tension (5.0 \pm 0.4 versus $4.8 \pm 0.4 \mathrm{kPa})$ and an increase in cardiac frequency $\left(87 \pm 13\right.$ versus $95 \pm 13$ beats $\left.\mathrm{min}^{-1}\right)$ were observed. A pre-flight $\mathrm{Pa}, \mathrm{O}_{2}$ of $>9.3 \mathrm{kPa}$ did not secure an acceptable in-flight $\mathrm{Pa}, \mathrm{O}_{2}$. Aerobic capacity showed the strongest correlation with in-flight $\mathrm{Pa}, \mathrm{O}_{2}$.

In conclusion, following an initial decrease in arterial oxygen tension, chronic obstructive pulmonary disease patients in a stable state of their disease seem to maintain a stable arterial oxygen tension throughout a flight of intermediate duration, except when walking along the aisle. However, a decrease in arterial carbon dioxide tension, indicating compensatory hyperventilation, could imply a risk of respiratory fatigue during longer flights.

KEYWORDS: Altitude, cabin pressure, chronic obstructive pulmonary disease, commercial aircraft, hypoxaemia

everal guidelines regarding the pre-flight evaluation of chronic obstructive pulmonary disease (COPD) patients have been published [1-6]. There is, however, disparity between guidelines, regarding both the lowest acceptable in-flight arterial oxygen tension $\left(\mathrm{Pa}, \mathrm{O}_{2}\right)$ and methods of pre-flight evaluation. Supplemental oxygen is recommended for patients in whom a drop in $\mathrm{Pa}_{1} \mathrm{O}_{2}$ to $<6.7 \mathrm{kPa}(<50 \mathrm{mmHg})$ $[1,2,6]$ or $<7.3 \mathrm{kPa}(<55 \mathrm{mmHg})$ [3] is anticipated. Suggested screening tests for pre-flight evaluation are: a forced expiratory volume in one second (FEV1) of $<50 \%$ of the predicted value [3], a forced vital capacity (FVC) of $<50 \%$ pred [3], a single-breath transfer factor of the lung for carbon monoxide $(T \mathrm{~L}, \mathrm{CO})$ of $<50 \%$ pred $[3,6]$, percutaneous oxygen saturation $\left(\mathrm{Sp}, \mathrm{O}_{2}\right)$ of $<95 \%$ [1], and becoming severely dyspnoeic by walking $50 \mathrm{~m}[1,3,5]$. Recommended tests for further preflight evaluation are: arterial blood gas analyses, prediction of in-flight hypoxaemia from nomograms or equations, hypoxic gas mixture testing, and hypobaric chamber testing [1-6]. A pre-flight
$\mathrm{Pa}_{1} \mathrm{O}_{2}$ of $>9.3 \mathrm{kPa}(>70 \mathrm{mmHg})$ is claimed to be sufficient for maintaining an acceptable in-flight $\mathrm{Pa}_{1} \mathrm{O}_{2}[3,4,7-10]$. Some of these procedures have recently been challenged. In a hypobaric chamber study of COPD patients exposed to a simulated altitude of $2,438 \mathrm{~m}$, a pre-flight $\mathrm{Pa}_{\mathrm{a}_{2}} \mathrm{O}_{2}$ of $>9.3 \mathrm{kPa}$ was shown not to predict an acceptable $\mathrm{Pa}_{1} \mathrm{O}_{2}$ under hypobaric conditions [11]. Furthermore, the in-flight $\mathrm{Pa}_{1} \mathrm{O}_{2}$ was not predictable from either spirometric values or a recommended regression equation [11].

Studies of COPD patients during regular flights have been lacking. Such studies should take into account the duration of hypobaric hypoxia, exercise tolerance under hypobaric conditions [12], the clinical consequences of transient hypoxaemia [13], and, in addition, pre- and in-flight stresses, such as carrying luggage, long walks to the gate, cramped seating conditions, dining, low humidity, turbulence, etc.

The aim of the present study was to evaluate the effect of a routine commercial flight on arterial
AFFILIATIONS

*Dept of Pulmonary Medicine, Ullevål University Hospital, Oslo, and \#Glittreklinikken, Hakadal, Norway.

CORRESPONDENCE

A. Akerø

Dept of Pulmonary Medicine Ullevål University Hospital 0407 Oslo

Norway

Fax: 4723015963

E-mail: aina.akero@uus.no

Received

August 092004

Accepted after revision:

November 192004 
blood gas levels, $\mathrm{Sp}, \mathrm{O}_{2}$ and clinical symptoms in patients with COPD. The patients were tested both when seated and when walking along the aisle, at a cabin pressure representative of most commercial flights [8]. The aim was also to study whether pre-flight spirometric values, blood gas levels at sea level, maximal oxygen consumption during exercise or a recommended regression equation [7] could predict in-flight hypoxaemia.

\section{METHODS \\ Subjects}

The authors established contact with a COPD rehabilitation project transporting patients from Norway to a recreation centre on the island of Grand Canary (Spain). The 18 patients, 13 males and five females, suffered from moderate or severe COPD, according to the criteria of the Global Initiative for Chronic Obstructive Lung Disease (GOLD) [4], with an FEV1 of $<80 \%$ pred, and had been without COPD exacerbations for $\geqslant 2$ months. All but one used daily bronchodilating medication, and three patients were also taking low doses of prednisolone. None showed symptoms of heart disease, pulmonary diseases other than COPD, neurological disease or anaemia.

All patients had been evaluated in advance by the rehabilitation project's chest physician and found fit for air travel without supplemental oxygen, on the basis of a pre-flight $\mathrm{Sp}, \mathrm{O}_{2}$ of $\geqslant 94 \%$ at rest at sea level, corresponding to a $\mathrm{Pa}_{1} \mathrm{O}_{2}$ of $>9.3 \mathrm{kPa}[1]$, and a self-reported ability to walk $50 \mathrm{~m}$ without becoming severely dyspnoeic $[1,3,5,14]$.

The Regional Committee for Medical Research Ethics, Health Region East (Oslo, Norway), Norwegian Air Traffic and Airport Management (Oslo, Norway), and the airline Novair (Stockholm, Sweden) all approved the study, and written informed consent was obtained from all participants.

\section{Pre-flight tests}

Additional sea-level pre-flight tests were performed, and the results blinded. Lung function tests were performed using a MasterLab (Jaeger Toennies, Würzburg, Germany). Before departure (24-48 h), $\mathrm{Sp}, \mathrm{O}_{2}$ and cardiac frequency (Pulsox-3i; Minolta, Osaka, Japan) were measured in the sitting position after $5 \mathrm{~min}$ at rest, as were arterial blood gas levels, from a blood sample drawn from the radial artery. The samples were immediately analysed using two portable blood gas analysers (ABL77; Radiometer, Copenhagen, Denmark). The blood gas analysers had been tested in a hypobaric chamber at a pressure equivalent to an altitude of 2,438 m (8,000 ft), showing similar values at this altitude and at sea level.

The patients exercised on a treadmill (Jaeger LE 2000 and Oxycon Champion; both Jaeger Toennies) until exhaustion. Aerobic capacity was defined as the maximum oxygen consumption divided by weight. One of the patients did not tolerate the mouthpiece, and so could not be tested. The treadmill exercise confirmed that each participant was able to walk $50 \mathrm{~m}$ without becoming severely dyspnoeic (Borg 5). Dyspnoea was scored using the Borg category ratio 0-10 (CR10) scale [15].

Retrospectively, in-flight $\mathrm{Pa}_{\mathrm{a}} \mathrm{O}_{2}$ was also estimated using the regression equation proposed by GoNG et al. [7] for nonhypercapnic COPD patients at $1,524 \mathrm{~m}(5,000 \mathrm{ft})$ to $3,048 \mathrm{~m}(10,000 \mathrm{ft})$.

\section{In-flight tests}

The study was performed in a Boeing 737-800 aircraft, departing from Oslo International Airport (Gardermoen, Norway) to Las Palmas (Grand Canary, Spain). It was a nonsmoking flight of duration $5 \mathrm{~h} 40 \mathrm{~min}$, with a mean cabin pressure equivalent to an altitude of $1,829 \mathrm{~m}(6,000 \mathrm{ft})$ at cruising altitude. Cabin pressure was monitored with a barometer (WIKA Transmitter S-10; Wiegand, Klingenberg, Germany) during the flight.

The blood gas analysers were calibrated $30 \mathrm{~min}$ after reaching the cruising altitude, and arterial blood gas levels were measured after $5 \mathrm{~min}$ at rest in the sitting position and immediately analysed. The same procedure was repeated 30 min after a meal without alcohol after $\sim 4 \mathrm{~h}$ of flight. $S \mathrm{p}, \mathrm{O}_{2}$ and cardiac frequency were measured simultaneously with arterial blood gas levels, and, in addition, when the patients walked along the aisle.

Dyspnoea was scored using the Borg CR10 scale both at rest and during light exercise, and clinical symptoms were recorded by the investigators.

\section{Statistical analysis}

Descriptive data are presented as mean $\pm \mathrm{SD}$, unless otherwise specified. Paired t-tests were used to evaluate differences between variables at sea level and during flight. Two-tailed p-values of $<0.05$ were considered significant. All variables were normally distributed, as assessed by Shapiro-Wilk test statistics. Relationships between $\mathrm{Pa}_{1} \mathrm{O}_{2}$ at altitude and lung function, oximetric results, arterial blood gas levels and treadmill results at sea level were assessed from linear regression analysis using Pearson's correlation coefficient, and, in addition, a stepwise linear regression model.

\section{RESULTS}

\section{Pre-flight tests}

The results of the lung function tests, arterial blood gas levels at sea level and aerobic capacity are presented in table 1.

\section{In-flight tests}

One hour after reaching cruising altitude, all participants exhibited a considerably lower $\mathrm{Pa}_{1} \mathrm{O}_{2}$ than at sea level $(8.6 \pm 0.8$ versus $10.3 \pm 1.2 \mathrm{kPa}$ at sea level, $\mathrm{p}<0.001$, fig. $1 \mathrm{a})$. No further decrease in $\mathrm{Pa}_{1} \mathrm{O}_{2}$ was observed after $4 \mathrm{~h}$ (8.6 \pm 0.8 versus $8.7 \pm 1.1 \mathrm{kPa}$ after $4 \mathrm{~h}$ ).

The arterial carbon dioxide tension $\left(\mathrm{Pa}_{\mathrm{a}} \mathrm{CO}_{2}\right)$ at sea level was $5.0 \pm 0.4 \mathrm{kPa}$. No significant reduction in $\mathrm{Pa}_{1} \mathrm{CO}_{2}$ was observed after $1 \mathrm{~h}$ of flight $(4.9 \pm 0.4 \mathrm{kPa})$. After $4 \mathrm{~h}$, in-flight $\mathrm{Pa}_{\mathrm{a}} \mathrm{CO}_{2}$ decreased significantly compared with values obtained after $1 \mathrm{~h}(4.8 \pm 0.4$ versus $4.9 \pm 0.4 \mathrm{kPa}$ after $1 \mathrm{~h}, \mathrm{p}<0.05)$ and at sea level ( $4.8 \pm 0.4$ versus $5.0 \pm 0.4 \mathrm{kPa}$ at sea level, $\mathrm{p}<0.001$, fig. $1 \mathrm{~b}$ ). Similarly, there was a significant increase in cardiac frequency after $4 \mathrm{~h}$ of flight compared with sea level ( $95 \pm 13$ versus $87 \pm 13$ beats $\cdot \mathrm{min}^{-1}, \mathrm{p}<0.05$, fig. 1c).

The $S \mathrm{p}, \mathrm{O}_{2}$ at sea level was $96 \pm 1 \%$. After $1 \mathrm{~h}$ of flight, $\mathrm{Sp}_{\mathrm{p}} \mathrm{O}_{2}$ was reduced to $90 \pm 4 \%(p<0.001$, fig $1 \mathrm{~d})$. At rest, there was no further reduction in $\mathrm{Sp}_{\mathrm{p}} \mathrm{O}_{2}$ during the flight. When walking 
TABLE 1 Demographics, lung function, arterial blood gas levels and aerobic capacity before flight\#

\begin{tabular}{|c|c|c|}
\hline & Absolute value & Relative value \% pred \\
\hline \multicolumn{3}{|l|}{ Demographics } \\
\hline Height $\mathrm{cm}$ & $174 \pm 10(156-189)$ & \\
\hline Weight kg & $79 \pm 20(46-120)$ & \\
\hline \multicolumn{3}{|l|}{ Resting values } \\
\hline$T \mathrm{~L}, \mathrm{CO} \mathrm{mmol} \cdot \mathrm{min}^{-1} \cdot \mathrm{kPa}^{-1}$ & $5.67 \pm 2.83(2.00-11.22)$ & $62 \pm 30(25-106)$ \\
\hline $\mathrm{Pa}, \mathrm{O}_{2}, \mathrm{SL} \mathrm{kPa}$ & $10.3 \pm 1.2(8.6-12.1)$ & \\
\hline $\mathrm{Sp}, \mathrm{O}_{2}, \mathrm{SL} \%$ & $96 \pm 1(94-98)$ & \\
\hline $\mathrm{Pa}, \mathrm{CO}_{2}, \mathrm{SL} \mathrm{kPa}$ & $5.0 \pm 0.4(4.3-5.6)$ & \\
\hline \multicolumn{3}{|l|}{ Exercise data } \\
\hline Aerobic capacity $\mathrm{mL} \cdot \mathrm{min}^{-1} \cdot \mathrm{kg}^{-1}$ & $20.6 \pm 5.3(13.8-34.8)$ & \\
\hline
\end{tabular}

along the aisle, however, the $\mathrm{Sp}, \mathrm{O}_{2}$ decreased significantly to $87 \pm 4 \%(\mathrm{p}<0.001$, fig $2 \mathrm{a})$.

Both at rest and during light exercise, the majority of the patients tolerated the hypobaric hypoxia well (fig. 3). At rest, $13(73 \%)$ patients reported having no feeling of dyspnoea at all (Borg 0$)$, three (17\%) very weak or weak dyspnoea (Borg 1-2), one $(6 \%)$ moderate dyspnoea (Borg 3) and one (6\%) strong dyspnoea (Borg 5). During slow walking along the aisle, 10 $(56 \%)$ patients experienced no dyspnoea (Borg 0), four $(22 \%)$ moderate dyspnoea (Borg 3) and three (17\%) strong dyspnoea (Borg 5). The patient with strong dyspnoea at rest experienced very strong dyspnoea when walking (Borg 7). This participant also experienced headache. None of the other participants experienced hypoxia-related symptoms.

\section{Relationship between pre-flight values and in-flight $\mathrm{Pa}, \mathrm{O}_{2}$}

There was a significant correlation between aerobic capacity and in-flight $\mathrm{Pa}_{2} \mathrm{O}_{2}$ after both $1 \mathrm{~h}(\mathrm{r}=0.75, \mathrm{p}<0.001)$ and $4 \mathrm{~h}$ $(\mathrm{r}=0.80, \mathrm{p}<0.001)$ of flight (fig. $4 \mathrm{a})$.

The $\mathrm{Pa}, \mathrm{O}_{2}$ at sea level $\left(\mathrm{Pa}_{\mathrm{a}} \mathrm{O}_{2}, \mathrm{SL}\right)$ also correlated with in-flight $\mathrm{Pa}_{\mathrm{a}} \mathrm{O}_{2}$, in both samples taken after $1 \mathrm{~h}(\mathrm{r}=0.73, \mathrm{p}<0.001)$ and $4 \mathrm{~h}$ $(\mathrm{r}=0.65, \mathrm{p}<0.01)$ of flight (fig. $4 \mathrm{~b})$.

In addition, $\mathrm{TL}, \mathrm{CO}(\%$ pred) correlated significantly with inflight $\mathrm{Pa}, \mathrm{O}_{2}$ in samples taken after $1 \mathrm{~h}(\mathrm{r}=0.49, \mathrm{p}<0.05)$ and $4 \mathrm{~h}$ $(\mathrm{r}=0.75, \mathrm{p}<0.001)$. No correlation was observed between inflight $\mathrm{Pa}, \mathrm{O}_{2}$ and any of the pre-flight spirometric parameters (FEV1 and FVC, both \% pred).

Using a stepwise linear regression model with in-flight $\mathrm{Pa}_{\mathrm{a}_{2}} \mathrm{O}_{2}$ as the dependent variable, aerobic capacity and $\mathrm{Pa}_{2} \mathrm{O}_{2}, \mathrm{SL}$ contributed significantly in a regression for in-flight $\mathrm{Pa}_{\mathrm{a}} \mathrm{O}_{2}$ after $1 \mathrm{~h}$. For in-flight $\mathrm{Pa}_{1} \mathrm{O}_{2}$ after $4 \mathrm{~h}$, only aerobic capacity was a significant regressor. Including $\mathrm{TL}, \mathrm{CO}$ (\% pred) did not contribute significantly in the multiple regression analysis for in-flight $\mathrm{Pa}_{\mathrm{a}} \mathrm{O}_{2}$ after either 1 or $4 \mathrm{~h}$.

\section{Prediction of in-flight $\mathrm{Pa}, \mathrm{O}_{2}$ from a regression equation}

Using the regression equation developed by GoNG et al. [7], at the present altitude of $1,829 \mathrm{~m}$, a significantly lower calculated than measured $\mathrm{Pa}_{2} \mathrm{O}_{2}$ was found. The difference between predicted and measured in-flight $\mathrm{Pa}_{2} \mathrm{O}_{2}$ was $-0.8 \pm 0.8 \mathrm{kPa}$ (range $-2.0-0.8 \mathrm{kPa}, \mathrm{p}<0.001$ ).

\section{DISCUSSION}

In the present investigation, 18 COPD patients were studied during a regular commercial flight. Their $\mathrm{Pa}, \mathrm{O}_{2}$ and $\mathrm{Sp}, \mathrm{O}_{2}$ decreased significantly from sea level to in-flight values, but remained stable throughout the flight, except for a marked desaturation when walking along the aisle. The $\mathrm{Pa}, \mathrm{CO}_{2}$ decreased and cardiac frequency increased after $4 \mathrm{~h}$ at cruising altitude. All but one patient tolerated the flight well. Aerobic capacity showed the strongest correlation with in-flight $\mathrm{Pa}, \mathrm{O}_{2}$.

The guidelines regarding pre-flight assessment of COPD patients are based primarily on experimental studies with hypoxic gas inhalation or hypobaric chamber testing. These studies do not take into account stresses that are imposed on passengers during regular flights, nor the duration of the hypobaric hypoxia [1-6]. These aspects are included in the present study, in which the effects of hypobaric hypoxia were studied in a group of COPD patients during a regular flight lasting $5 \mathrm{~h} 40 \mathrm{~min}$. The 1,829 $\mathrm{m}$ cruising altitude in the present study has been shown to be the mean altitude during most commercial flights [8]. During longer intercontinental flights, however, it is necessary to consider the possibility of higher cruising altitudes with lower cabin pressures. Alcohol was avoided during the flight, and this may differ from the normal flight situation for some of the present patients. Owing to the limited number of patients, the present results do not necessarily apply to all patients with COPD.

In the present study, $\mathrm{Pa}_{2} \mathrm{O}_{2}$ dropped significantly from sea level to in-flight values. It was of interest to observe that the patients maintained their $\mathrm{Pa}_{1} \mathrm{O}_{2}$, with no further decrease in $\mathrm{Pa}_{1} \mathrm{O}_{2}$ after 

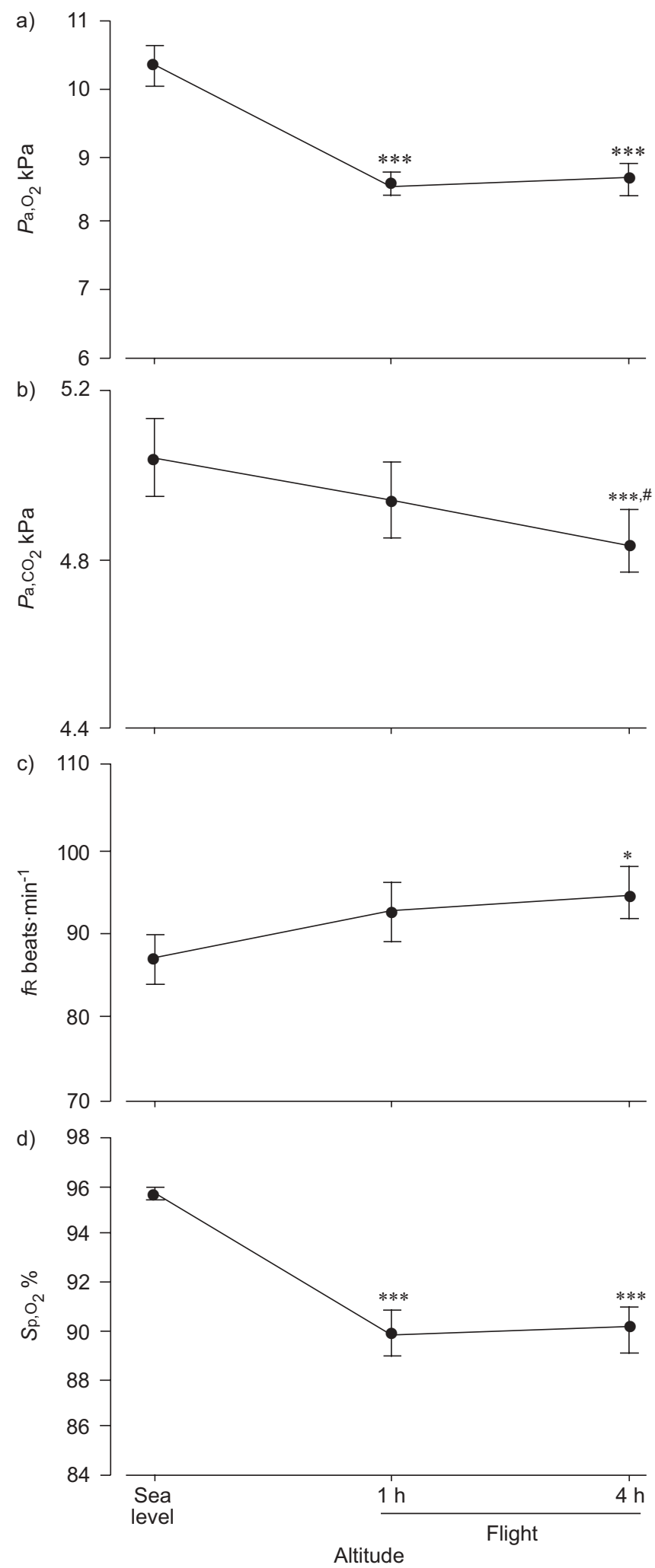

FIGURE 1. Arterial blood gas levels and cardiac frequency (fR) at rest at sea level, and during flight at cruising altitude $(1,829 \mathrm{~m})$ after 1 and $4 \mathrm{~h}$ : a) arterial oxygen tension $\left.\left(\mathrm{Pa}_{1} \mathrm{O}_{2}\right), \mathrm{b}\right)$ arterial carbon dioxide tension $\left.\left(\mathrm{Pa}_{\mathrm{a}} \mathrm{CO}_{2}\right), \mathrm{C}\right) \mathrm{fR}_{\mathrm{R}}$, and $\mathrm{d}$ ) percutaneous oxygen saturation $\left(\mathrm{Sp}, \mathrm{O}_{2}\right)$. Data are presented as mean $\pm \mathrm{SEM} .{ }^{*}$ : $p<0.05$; $* \star *: p<0.001$ versus sea level; $\#: p<0.05$ versus in-flight value after $1 \mathrm{~h}$.
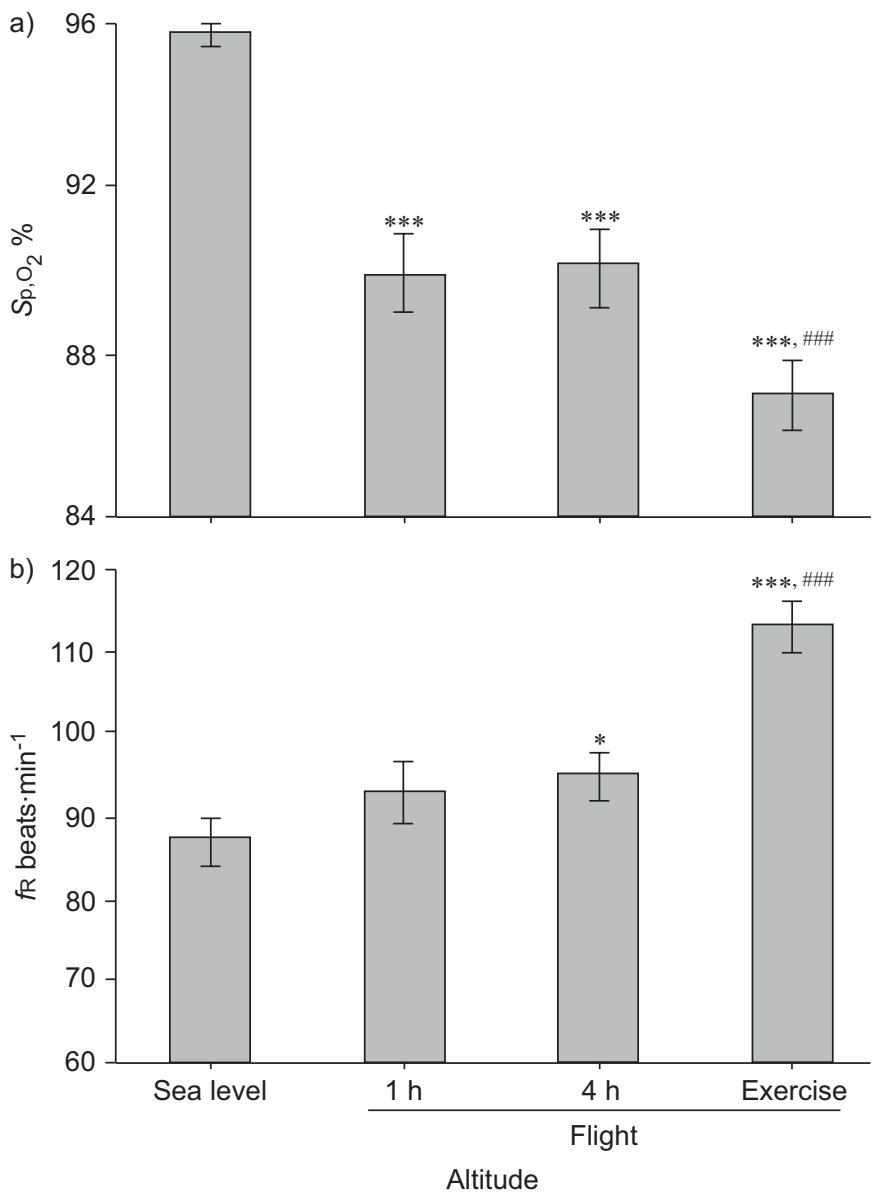

FIGURE 2. a) Percutaneous oxygen saturation $\left(\mathrm{Sp}, \mathrm{O}_{2}\right)$ and b) cardiac frequency $(\mathrm{f})$ at rest at sea level, and during flight at cruising altitude $(1,829 \mathrm{~m})$ during rest and exercise. Data are presented as mean \pm SEM. ${ }^{*}: p<0.05$; $* * *$ : $p<0.001$ versus sea level; \#\#\#: $p<0.001$ versus in-flight value after $4 \mathrm{~h}$ at rest.

$4 \mathrm{~h}$ at cruising altitude. However, their $\mathrm{Pa}_{1} \mathrm{CO}_{2}$ decreased towards the end of the flight, suggesting that the patients were increasing their ventilation to maintain arterial oxygen saturation. This ventilatory increase corresponded to an increase in cardiac frequency. Both hyperventilation and tachycardia are known physiological responses to hypoxaemia $[7,11]$. Even if the patients were able to maintain a stable $\mathrm{Pa}_{\mathrm{a}} \mathrm{O}_{2}$ during the present flight of intermediate duration, the possible compensatory hyperventilation may be of importance, since, during long-distance flights, COPD patients might experience desaturation due to respiratory fatigue. Thus, consideration of flight duration may be relevant when performing pre-flight assessments.

The $\mathrm{Sp}_{\mathrm{P}} \mathrm{O}_{2}$ fell significantly during light exercise, and five (22\%) patients exhibited $\mathrm{Sp}, \mathrm{O}_{2}$ of $\leqslant 84 \%$, below recommended values [1]. The present findings confirm the results from a previous study [11], in which blood gas levels in patients with COPD, tested in an altitude chamber equivalent to 2,438 $\mathrm{m}$, dropped significantly during light exercise, leading to severe hypoxaemia in some patients. The previous study also showed that the desaturation observed during light exercise under hypobaric hypoxia was more pronounced than during comparable 


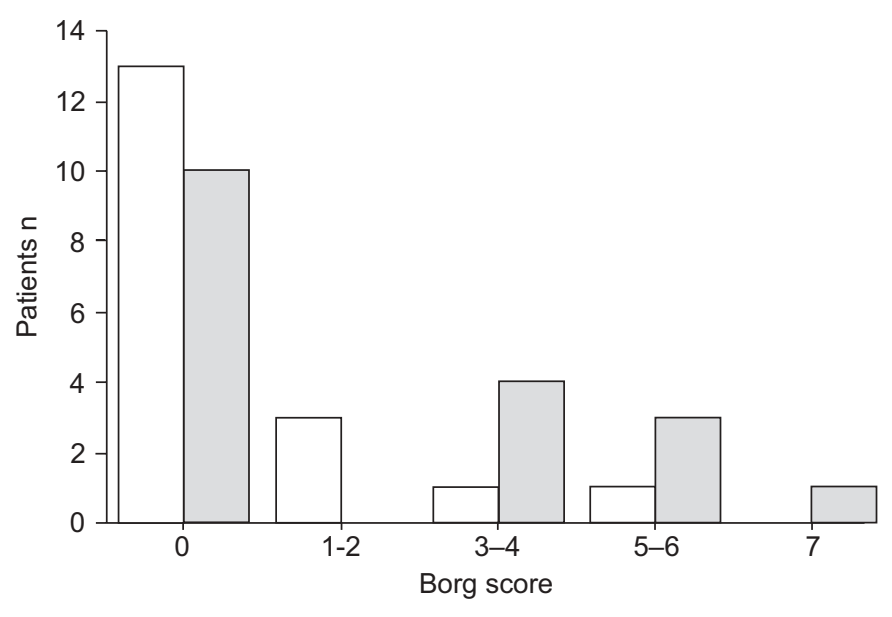

FIGURE 3. In-flight Borg score at rest $(\square)$ and during exercise ( $\square$ ).

exercise at sea level [11]. The aspect of physical exercise during air travel has not been addressed in the published guidelines, but should perhaps be a topic in the pre-flight evaluation of patients with COPD [10].

The clinical significance of temporary altitude-induced hypoxaemia in patients with COPD has not been fully elucidated
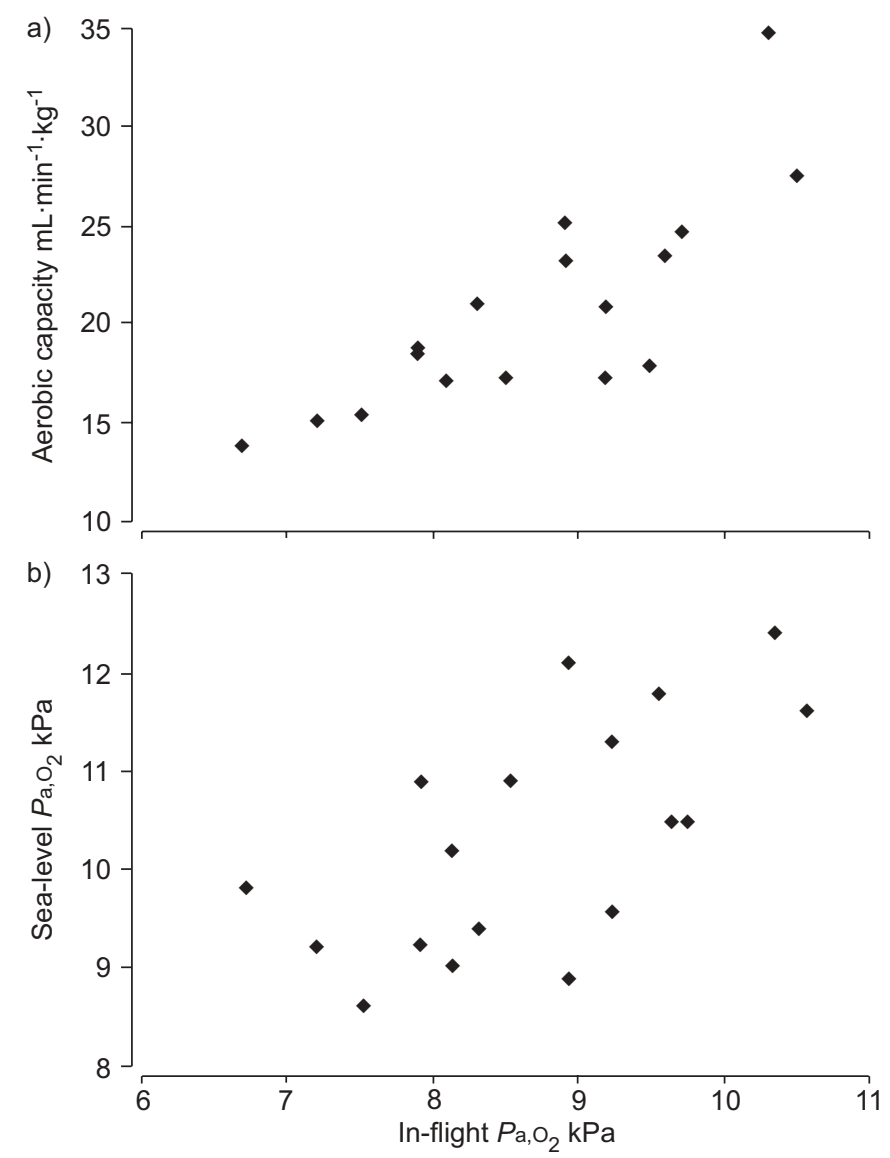

FIGURE 4. Correlation of arterial oxygen tension $\left(\mathrm{Pa}_{\mathrm{a}} \mathrm{O}_{2}\right)$ after $4 \mathrm{~h}$ of flight with a) aerobic capacity and b) $\mathrm{Pa}_{\mathrm{a}} \mathrm{O}_{2}$ at sea level.
$[1,16]$. It is difficult to produce objective information about hypoxia-related symptoms, because the earliest symptoms may be vague, with altered behaviour, varying from indifference to excitation, perhaps modifying self-reported symptomatic responses to hypoxia [14, 17]. In the present study, only one subject experienced headache, which was interpreted as a hypoxia-related symptom, and was given supplemental oxygen for the rest of the flight. Interestingly, this patient exhibited a pre-flight $\mathrm{Pa}_{1} \mathrm{O}_{2}$ of $9.8 \mathrm{kPa}$, dropping to $6.7 \mathrm{kPa}$ after $4 \mathrm{~h}$ of flight. This patient experienced strong dyspnoea, and admitted to having a COPD exacerbation starting on the morning of departure. The other participants did not complain of hypoxiarelated symptoms. The present findings of little or no symptoms among the participants during the flight are in line with findings in previous studies of COPD patients under hypoxic conditions $[7,9,11,18,19]$. Taken together with the large number of COPD patients travelling in commercial aircraft, apparently without ill effects [20-23], both the present and previous studies suggest that COPD patients with stable symptoms, without associated cardiovascular disease, tolerate moderate short-term hypoxia well. However, patients with unstable symptoms should probably refrain from flying, even if previously found fit to fly without supplemental oxygen.

All participants were able to walk $50 \mathrm{~m}$ without severe dyspnoea, and all of them, except the patient who experienced an exacerbation on the day of departure, tolerated the flight well. This finding, during a regular flight, is in concordance with studies recommending walking a distance of $50 \mathrm{~m}$ as a simple clinical test of fitness to fly $[1,3,5,14]$. A strong correlation between pre-flight aerobic capacity and in-flight $\mathrm{Pa}_{1} \mathrm{O}_{2}$ were found, in both the present study and a previous study on COPD patients in a hypobaric chamber [11]. This is supported by the significant contribution of aerobic capacity using a stepwise linear regression model with in-flight $\mathrm{Pa}_{2} \mathrm{O}_{2}$ as the dependent variable. The present study was not designed to test the usefulness of pre-flight exercise testing, but, in the authors' opinion, such testing might be of value. Thus, it would be of interest to address this topic in future studies. In the present study, $\mathrm{Pa}, \mathrm{O}_{2}$, SL also correlated positively with inflight $\mathrm{Pa}_{1} \mathrm{O}_{2}$. Such correlation was not observed in the previous hypobaric chamber study [11]. This discrepancy may be explained by differences in method (hypobaric chamber versus commercial flight), altitude and patient population. Using a stepwise linear regression model, $\mathrm{Pa}_{2} \mathrm{O}_{2}, \mathrm{SL}$ contributed significantly in a regression for in-flight $P \mathrm{~Pa}_{2} \mathrm{O}_{2}$ after $1 \mathrm{~h}$, but not after $4 \mathrm{~h}$. The present study was not designed to test whether a $\mathrm{Pa}_{1} \mathrm{O}_{2}, \mathrm{SL}$ of $>9.3 \mathrm{kPa}$ is sufficient to maintain an adequate inflight $\mathrm{Pa}_{2} \mathrm{O}_{2}$, but it was found that one patient with a $\mathrm{Pa}, \mathrm{O}_{2}, \mathrm{SL}$ of $>9.3 \mathrm{kPa}$ desaturated to a resting in-flight $\mathrm{Pa}_{1} \mathrm{O}_{2}$ of $6.7 \mathrm{kPa}$, and three patients with $\mathrm{Pa}, \mathrm{O}_{2}, \mathrm{SL}$ of $>9.3 \mathrm{kPa}$ desaturated to $\mathrm{Sp}, \mathrm{O}_{2}$ of $\leqslant 84 \%$ during light exercise. In the present authors' opinion, the decrease in $\mathrm{Sp}_{\mathrm{p}} \mathrm{O}_{2}$ during exercise could not have been predicted from the patients' $\mathrm{Pa}, \mathrm{O}_{2}, \mathrm{SL}$. The present findings are in accordance with the hypobaric chamber study, from which it was concluded that a $\mathrm{Pa}, \mathrm{O}_{2}, \mathrm{SL}$ of $>9.3 \mathrm{kPa}$ could not exclude in-flight hypoxaemia, either at rest or during light exercise [11].

TL,CO (\% pred) was also found to correlate with in-flight $\mathrm{Pa}_{\mathrm{a}} \mathrm{O}_{2}$ after 1 and $4 \mathrm{~h}$, but, in a stepwise multiple regression model, the contribution of $T \mathrm{~L}, \mathrm{CO}$ ( $\%$ pred) was not significant. There have been discussions about the usefulness of spirometric 
values in the pre-flight assessment of patients with COPD [9, $11,13,18,24-26]$. In the present study, no correlation was found between either FVC or FEV1 (both \% pred) and in-flight $\mathrm{Pa}, \mathrm{O}_{2}$.

Several equations have been developed in order to predict inflight $\mathrm{Pa}_{\mathrm{a}} \mathrm{O}_{2}$ on the basis of pre-flight parameters $[7,19,24,25$, 27]. Using an equation proposed by GONG and coworkers [7, 19], it was found that the estimated $\mathrm{Pa}_{1} \mathrm{O}_{2}$ was lower than the measured in-flight $\mathrm{Pa}_{1} \mathrm{O}_{2}$. This is in contradiction with a previous study [11], in which overestimation of $\mathrm{Pa}_{1} \mathrm{O}_{2}$ was found. These varying results underline the need for the validation of equations in separate patient populations before they can be used with confidence in the prediction of in-flight $\mathrm{Pa}_{\mathrm{a}} \mathrm{O}_{2}$.

In conclusion, this is the first study to report that chronic obstructive pulmonary disease patients with stable symptoms seem able to maintain a stable arterial oxygen tension throughout a commercial flight of intermediate duration. However, the decrease in arterial carbon dioxide tension could indicate compensatory hyperventilation, implying a possible risk of respiratory fatigue during longer flights. Further desaturation due to physical activity should also be taken into account. With regard to pre-flight testing, aerobic capacity showed the strongest correlation with in-flight arterial oxygen tension. A sea-level arterial oxygen tension of $>9.3 \mathrm{kPa}$ did not secure an acceptable in-flight arterial oxygen tension during light exercise. In spite of hypoxaemia, the flight was well tolerated, but, importantly, chronic obstructive pulmonary disease patients with unstable symptoms prior to departure should probably refrain from flying.

\section{ACKNOWLEDGEMENTS}

The authors would like to thank M. Ryg, F. Borchsenius and H. Mellem for their assistance with statistics and preparation of the manuscript, and T. Haugen for assistance in including the participants. Also, the enthusiastic cooperation of the subjects who participated in the study is gratefully acknowledged.

\section{REFERENCES}

1 British Thoracic Society Standards of Care Committee. Managing passengers with respiratory disease planning air travel: British Thoracic Society recommendations. Thorax 2002; 57: 289-304.

2 American Thoracic Society. ATS statement: standards for the diagnosis and care of patients with chronic obstructive pulmonary disease. Am J Respir Crit Care Med 1995; 152: S112-S113.

3 Aerospace Medical Association. Medical Guidelines for Air Travel. Aviat Space Environ Med 1996; 67: Suppl. 10, B1-B16.

4 NHLBI/WHO. Workshop report: Global Initiative for Chronic Obstructive Lung Disease (GOLD). Global Strategy for the Diagnosis, Management, and Prevention of Chronic Obstructive Pulmonary Disease (publication No. 2701). Bethesda, National Institutes of Health/ National Heart, Lung, and Blood Institute, 2001.

5 Lyznicki JM, Williams MA, Deitchman SD, Howe JP. Report of the AMA council on scientific affairs: medical oxygen and air travel. Aviat Space Environ Med 2000; 71: 827-831.
6 Siafakas NM, Vermeire P, Pride NB, et al. Optimal assessment and management of chronic obstructive pulmonary disease (COPD). Eur Respir J 1995; 8: 1398-1420.

7 Gong H Jr, Tashkin DP, Lee EY, Simmons MS. Hypoxiaaltitude simulation test. Evaluation of patient with chronic airway obstruction. Am Rev Respir Dis 1984; 130: 980-986.

8 Cottrell JJ. Altitude exposure during aircraft flight. Flying higher. Chest 1988; 93: 81-84.

9 Schwartz JS, Bencowitz HZ, Moser KM. Air travel hypoxemia with chronic obstructive pulmonary disease. Ann Intern Med 1984; 100: 473-477.

10 Naeije R. Preflight medical screening of patients. Eur Respir J 2000; 16: 197-199.

11 Christensen CC, Ryg M, Refvem OK, Skjønsberg OH. Development of severe hypoxaemia in chronic obstructive pulmonary disease patients at 2,438 $\mathrm{m}(8,000 \mathrm{ft})$ altitude. Eur Respir I 2000; 15: 635-639.

12 Coker RK, Partridge MR. Assessing the risk of hypoxia in flight: the need for more rational guidelines. Eur Respir J 2000; 15: 128-130.

13 Vohra KP, Klocke RA. Detection and correction of hypoxemia associated with air travel. Am Rev Respir Dis 1993; 148: 1215-1219.

14 Mills FJ, Harding RM. Fitness to travel by air. I: physiological considerations. BMJ 1983; 286: 1269-1271.

15 Borg G. The Borg CR 10 Scale. In: Borg G, ed. Borg's Perceived Exertion and Pain Scales. Champaign, IL, Human Kinetics, 1998; pp. 623-624.

16 Gong H Jr. Air travel and oxygen therapy in cardiopulmonary patients. Chest 1992; 101: 1104-1113.

17 Harding RM, Mills FJ. Aviation medicine. Problems of altitude I: hypoxia and hyperventilation. BMJ 1983; 286: 1408-1410.

18 Robson AG, Hartung TK, Innes JA. Laboratory assessment of fitness to fly in patients with lung disease: a practical approach. Eur Respir J 2000; 16: 214-219.

19 Gong H. Advising pulmonary patients about commercial air travel. J Respir Dis 1990; 11: 484-499.

20 Rayman RB. Passenger safety, health, and comfort: a review. Aviat Space Environ Med 1997; 68: 432-440.

21 Speizer C, Rennie C, Breton H. Prevalence of in-flight medical emergencies on commercial airlines. Ann Emerg Med 1989; 18: 26-29.

22 Gong H Jr, Mark JA, Cowan MN. Preflight medical screenings of patients. Analysis of health and flight characteristics. Chest 1993; 104: 788-794.

23 Gong H Jr. Air travel and patients with chronic obstructive pulmonary disease. Ann Intern Med 1984; 100: 595-597.

24 Dillard TA, Berg BW, Rajagopal KR, Dooley JW, Mehm WJ. Hypoxemia during air travel in patients with chronic obstructive pulmonary disease. Ann Intern Med 1989; 111: 362-367.

25 Dillard TA, Rosenberg AP, Berg BW. Hypoxemia during altitude exposure. A meta-analysis of chronic obstructive pulmonary disease. Chest 1993; 103: 422-425.

26 Dillard TA, Moores LK, Bilello KL, Phillips YY. The preflight evaluation. A comparison of the hypoxia inhalation test with hypobaric exposure. Chest 1995; 2: 352-357.

27 Mortazavi A, Eisenberg MJ, Langleben D, Ernst P, Schiff RL. Altitude-related hypoxia: assessment and management for passengers on commercial aircraft. Aviat Space Environ Med 2003; 74: 922-927. 